\title{
THERMAL CHARGING STUDY OF COMPRESSED EXPANDED NATURAL GRAPHITE/PHASE CHANGE MATERIAL COMPOSITES
}

\author{
Anne Mallow ${ }^{1}$, Omar Abdelaziz ${ }^{2}$, Samuel Graham, Jr. ${ }^{3 *}$ \\ ${ }^{1}$ Graduate Research Assistant, Georgia Institute of Technology, Atlanta, GA 30308, USA \\ ${ }^{2}$ Senior Research Staff and Group Leader, Building Equipment Group, Oak Ridge National \\ Laboratory, Oak Ridge, TN 37831, USA \\ ${ }^{3}$ Mechanical Engineering Professor, Georgia Institute of Technology, Atlanta, GA 30308, USA
}

\begin{abstract}
The thermal charging performance of paraffin wax combined with compressed expanded natural graphite foam was studied for different graphite bulk densities. Constant heat fluxes between 0.39 $\mathrm{W} / \mathrm{cm}^{2}$ and $1.55 \mathrm{~W} / \mathrm{cm}^{2}$ were applied, as well as a constant boundary temperature of $60^{\circ} \mathrm{C}$. Thermal charging experiments indicate that, in the design of thermal batteries, thermal conductivity of the composite alone is an insufficient metric to determine the influence of the graphite foam on the thermal energy storage. By dividing the latent heat of the composite by the time to end of melt for each applied boundary condition, the energy storage performance was calculated to show the effects of composite thermal conductivity, graphite bulk density, and latent heat capacity. For the experimental volume, the addition of graphite beyond a graphite bulk density of $100 \mathrm{~kg} / \mathrm{m}^{3}$ showed limited benefit on the energy storage performance due to the decrease in latent heat storage capacity. These experimental results are used to validate a numerical model to predict the time to melt and for future use in the design of heat exchangers with graphite-foam based phase change material composites. Size scale effects are explored parametrically with the validated model.
\end{abstract}

*Corresponding author. E-mail: sgraham@gatech.edu (Samuel Graham)

This manuscript has been authored by UT-Battelle, LLC under Contract No. DE-AC05-00OR22725 with the U.S. Department of Energy. The United States Government retains and the publisher, by accepting the article for publication, acknowledges that the United States Government retains a nonexclusive, paid-up, irrevocable, world-wide license to publish or reproduce the published form of this manuscript, or allow others to do so, for United States Government purposes. The Department of Energy will provide public access to these results of federally sponsored research in accordance with the DOE Public Access Plan (http://energy.gov/downloads/doe-public-access-plan). 


\section{Introduction}

Phase change materials (PCMs) have the ability to store thermal energy as latent heat over a nearly isothermal temperature range. Compared to sensible heat storage, properly chosen PCMs can store an order of magnitude more energy when undergoing phase change and, thus, are important materials for the design of systems with large effective thermal masses or thermal batteries in engineering systems. Organic PCMs, such as paraffin wax, present several advantages including their noncorrosive nature and ability to melt congruently (without phase separation), which results in safe and reliable performance [1]. Because of these qualities, organic PCMs have been proposed for use in latent heat thermal storage systems to increase the energy efficiency or performance of various systems such as cooling and heating in buildings, waste heat recovery, hot water heating, electronics cooling, and thermal comfort in vehicles [2]. The efficacy of these materials is reduced by their characteristic low thermal conductivity, which significantly limits the rate of thermal charging and discharging.

One of the methods used to increase the thermal charging of PCMs is the insertion of highly conductive porous foams within the PCM. Two common materials used to form conductive foams are metal and graphite [1, 3-7]. Compressed expanded natural graphite (CENG) foams are an attractive thermal enhancement material due to their high conductivity and low density [8] combined with being an inexpensive alternative to metal. Furthermore, CENG foams can be easily molded into various shapes to accommodate any geometry and maximize contact between the composite and the heat source.

CENG foam is produced by compressing expanded graphite (EG) flake into a compact porous matrix. Though the flake offers improvement in thermal conductivity of the PCM, by compressing the flake, a significant increase in thermal conductivity can be realized [8,9]. Expanded graphite is prepared by heat treating graphite flake intercalated with acid to cause rapid expansion of the graphite layers $[8,10]$. The amount of EG used is measured by bulk density, which is the mass of graphite in the sample volume. The phase change material can then be absorbed into the matrix through capillary forces between the liquid PCM and the CENG to form a highly conductive composite [8]. This saturation process is impacted by the compression because the pores can either spilt or collapse when the EG is compressed, potentially forming closed voids that are impenetrable by PCM. By studying the amount of PCM absorbed by the sample compared to the theoretical maximum, Py et al. [1] 
concluded that the higher the bulk density, the greater the volume of closed pores, which can result in a loss in mass of PCM contained in the composite and ultimately the thermal storage capacity. Additionally, Balima et al. [11] found that pore collapse is dependent on compression force as well as compression direction. While a higher compression force required of a greater CENG bulk density increased pore collapse, this phenomenon was found more significant in the direction parallel to compression.

The latent heat and thermal conductivity of the solid can be used to characterize the PCM/CENG composite as a function of the CENG bulk density of the graphite foam. While latent heat storage of the PCM decreases due to the addition of graphite as well air contained within closed pores formed during the compression process [1], thermal conductivity of the PCM increases [1, 8, 12, 13]. The thermal conductivity of composites formed with CENG bulk densities greater than $50 \mathrm{~kg} / \mathrm{m}^{3}$ has been found to be anisotropic: thermal conductivity of the sample in the compression direction is less than in the direction perpendicular to the compression [1]. In previous studies, the thermal conductivity of paraffin composites with a CENG bulk density of $350 \mathrm{~kg} / \mathrm{m}^{3}$ has been reported to be $70 \mathrm{~W} / \mathrm{mK}$ in the direction perpendicular to compaction and $10 \mathrm{~W} / \mathrm{mK}$ in the compression direction [1]. This arises due to the preferred orientation of the graphite flakes transverse to the compression direction that results in an increase in thermal conductivity, while limited benefit of additional graphite is seen along the compression direction.

In addition to studying the influence of CENG bulk density on the storage properties of the PCM composite, applications such as thermal management of a battery pack [8], thermal storage in a solar hot water system [12, 14], and general application in constant temperature conditions [15] have been considered. In these applied experiments, Mills et al. [8], Haillot et al. [14], and Zhong et al. [15] studied PCM composites enhanced by CENG foam with bulk densities of $210 \mathrm{~kg} / \mathrm{m}^{3}, 150 \mathrm{~kg} / \mathrm{m}^{3}$, and $70 \mathrm{~kg} / \mathrm{m}^{3}$, respectively. These three experiments investigated the thermal charging of the PCM/CENG composites, but comparison of composite performance remains a function of the thermal conductivity. Though the tradeoff between thermal conductivity and latent heat storage capacity of the composite is a common thermal performance metric, the non-linear phase change process introduces a need for comparative thermal charging experiments under the same boundary conditions to understand the rate of thermal response as a function of the CENG bulk density. 
In this work, the impact of CENG bulk density on the performance of paraffin wax undergoing phase change was investigated. PCM/CENG composites were characterized by thermal conductivity and latent heat measurements. Thermal charging experiments were conducted for various bulk densities and boundary conditions using a standard experimental sample with a constant heat flux or constant temperature on one boundary and insulated sides. Thermal charging response, quantified by the time to end of melt, was correlated with the CENG bulk density, thermal conductivity, and latent heat. The anisotropy in the thermal conductivity of CENG foams was considered for bulk densities greater than $50 \mathrm{~kg} / \mathrm{m}^{3}$. This experimental data was used to validate a numerical model, which was then used to study the effect of the size scale on the thermal charging rate and energy storage performance. Since the size of the thermal battery is often a constraint of the system and application dependent, the parametric study demonstrates the impact of boundary condition and size in determining the optimum graphite bulk density.

\section{Experimental description}

\subsection{Sample preparation}

Technical grade paraffin wax (Aldrich mp 53-57 ${ }^{\circ} \mathrm{C}$ ) was used as received for the phase change thermal storage material. Material properties for the paraffin wax are listed in Table 1. The transition temperatures and latent heat of paraffin wax and PCM/CENG composites were measured using the differential scanning calorimeter (DSC) technique (TA Instruments Q2000) with a heating and cooling speed of $5^{\circ} \mathrm{C} /$ minute. Solid-solid and solid-liquid transition temperatures were determined by the respective temperatures at each apex of the endothermic DSC curve. The viscosity of paraffin wax was measured using a parallel plate rheometer (TA Instruments ARES) with a shear rate of 300/ sec, and a hot disk thermal constant analyzer (Hot Disk TPS 2500 S) was used to characterize the sample thermal conductivity [10].

Table 1. Properties of paraffin wax used in experimentation.

\begin{tabular}{|c|c|c|c|c|c|c|}
\hline & \multicolumn{2}{|c|}{$\begin{array}{c}\text { Transition } \\
\text { Temperature }\left({ }^{\circ} \mathrm{C}\right)\end{array}$} & \multirow{2}{*}{$\begin{array}{c}\text { Thermal } \\
\text { Conductivity } \\
\text { at } 20^{\circ} \mathbf{C} \\
(\mathrm{W} / \mathrm{mK})\end{array}$} & \multirow{2}{*}{$\begin{array}{c}\text { Viscosity } \\
\text { at } 80^{\circ} \mathrm{C} \\
(\mathrm{Pa}-\mathrm{s})\end{array}$} & \multicolumn{2}{|c|}{ Latent Heat $(\mathrm{J} / \mathrm{g})$} \\
\hline & Solid-solid & Solid-liquid & & & Solid-solid & Solid-liquid \\
\hline $\begin{array}{l}\text { Paraffin } \\
\text { Wax }\end{array}$ & 35.4 & 55.2 & 0.28 & 0.0066 & 31.2 & 132.2 \\
\hline
\end{tabular}


Exfoliated graphite (Asbury Carbons 3772) was used as received. This expandable graphite was heated in a $1000 \mathrm{~W}$ microwave over two 30 second intervals to complete the expansion process. An optical image of the expanded graphite (EG) is shown in Figure 1 (left). Each worm of expanded graphite was approximately $1.5-2.0 \mathrm{~mm}$ long and about $0.4 \mathrm{~mm}$ wide. The morphology of the expanded graphite was examined using a Hitachi VP 3700 variable pressure scanning electron microscope (SEM).
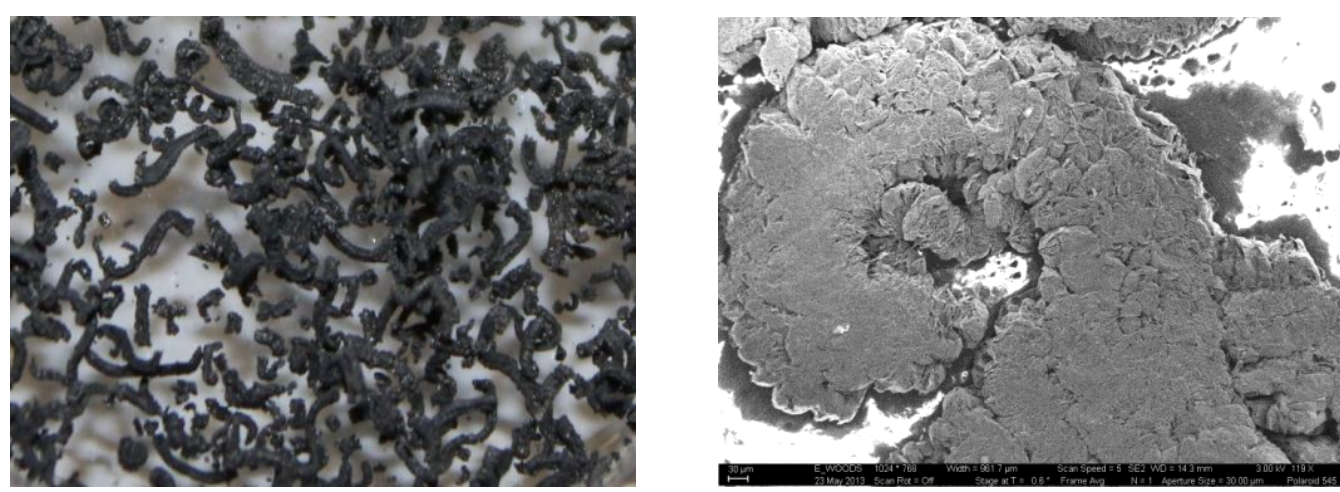

Figure 1. Optical image of EG (left); SEM image of EG at 119x magnification (right).

Each expanded graphite worm is an accordion style connection of graphene layers that have been separated during the heating under microwave energy and the release of the intercalated acid. An SEM image of EG at 119x magnification is shown in Figure 1 (right), while Figure 2 presents images at 1080x and 4020x magnification showing the expanded volume between the graphite layers.
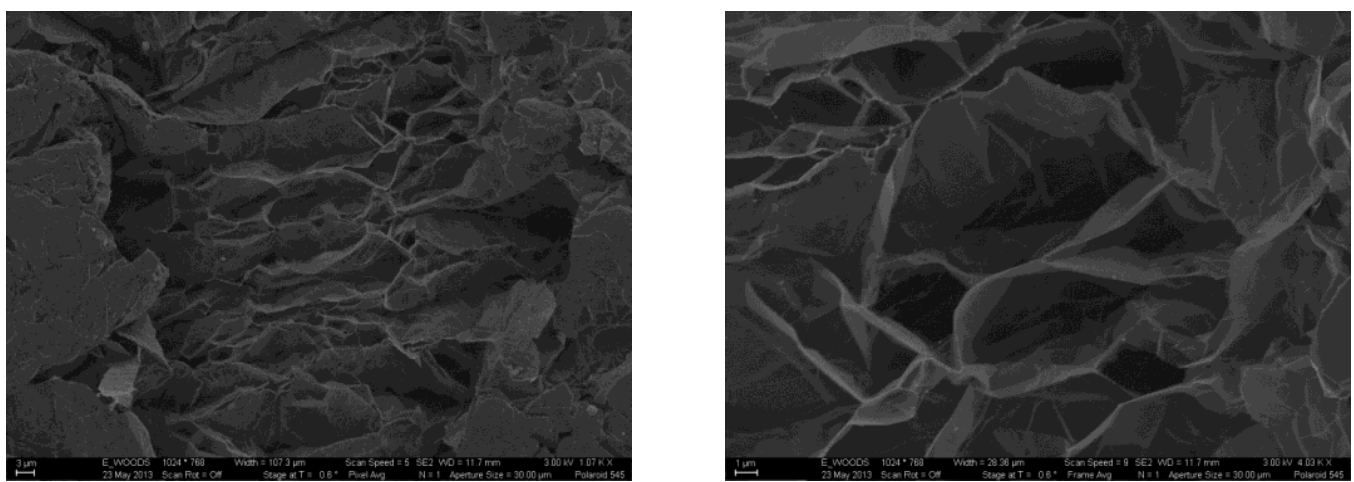

Figure 2. SEM images of EG at 1080x (left) and 4030x (right) magnification.

After the expansion process, the EG was manually compacted to the desired CENG bulk density by compressing in a stainless steel mold shown in Figure 3 (left). EG was loaded into the cylindrical container and then compressed until the punch was flush to the top of the container, forming a sample 
of volume 1.2e-4 $\mathrm{m}^{3}$. By measuring the mass of EG in the compression system, samples with bulk densities of $23,50,100$, and $143 \mathrm{~kg} / \mathrm{m}^{3}$ were formed.
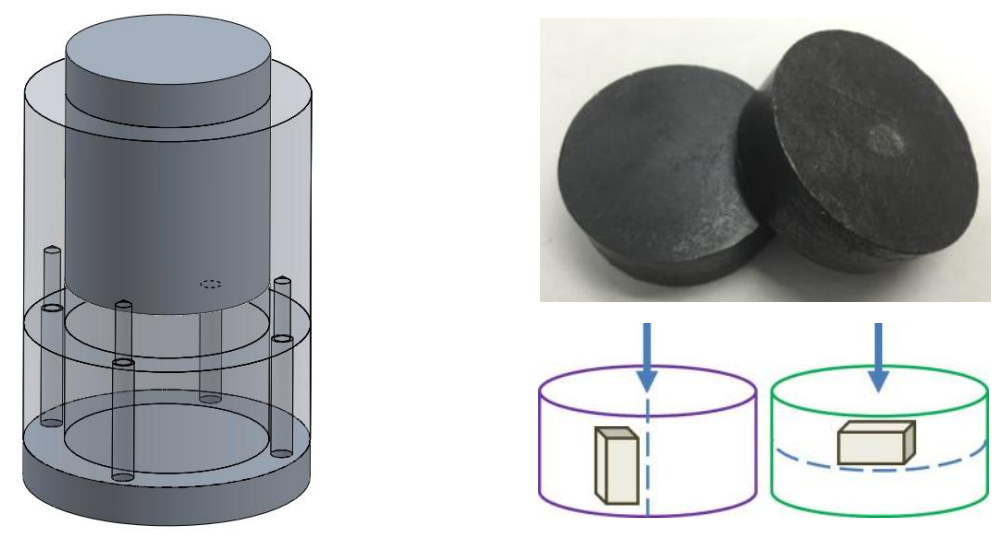

Figure 3. Compression system used to form samples (left); composite sample (top right); schematic of sample measurement orientations (bottom right).

The punch was then removed and paraffin wax was introduced to the compressed graphite in the bottom section of the mold to form the CENG composites. A solid block of paraffin wax was placed on top of the CENG and then the setup was inserted inside of a vacuum furnace at $80^{\circ} \mathrm{C}$ and held at $635 \mathrm{mmHg}$ vacuum. After saturation, the excess paraffin was poured from the mold to prevent supersaturation as the paraffin cooled and constricted. The solid CENG composite was removed from the mold as shown in Figure 3 (top right) and used in thermal conductivity and latent heat measurements as well as thermal charging experiments.

\subsection{Sample characterization}

Thermal conductivity of each composite was measured at $20^{\circ} \mathrm{C}$, while the composite latent heat and melting temperature were measured by ramping from $20^{\circ} \mathrm{C}$ to $80^{\circ} \mathrm{C}$. For the higher bulk densities, $100 \mathrm{~kg} / \mathrm{m}^{3}$ and $143 \mathrm{~kg} / \mathrm{m}^{3}$, anisotropy of the CENG was considered in the thermal conductivity measurements: thermal conductivity was measured along both cylinder axes of Figure 3 (bottom right), where the arrow represents the compression direction. Rectangular thermal charging experimental samples $(2.54 \times 2.54 \times 1.27 \mathrm{~cm})$ were cut from the disks used in thermal conductivity measurements. The anisotropy of the CENG was considered for $143 \mathrm{~kg} / \mathrm{m}^{3}$ composites during the thermal charging experiments as shown by the rectangular blocks of Figure 3 (bottom right). 
For the thermal charging experiments, thin film heaters with an adhesive backing and maximum output of $1.55 \mathrm{~W} / \mathrm{cm}^{2}$ were attached to an aluminium plate before being attached to each experimental sample using thermal grease. The samples were placed in acrylic test containers as shown in Figure 4 (left). The acrylic container was made with a $2.54 \mathrm{~cm} \times 2.54 \mathrm{~cm}$ hole into which the composite was placed. A square $0.15 \mathrm{~cm}$ thick aluminum plate with the adhesive heater was then placed on top of the sample with $0.5 \mathrm{~mm}$ of thermal grease. Figure 4 (right) presents a schematic of the test sample.
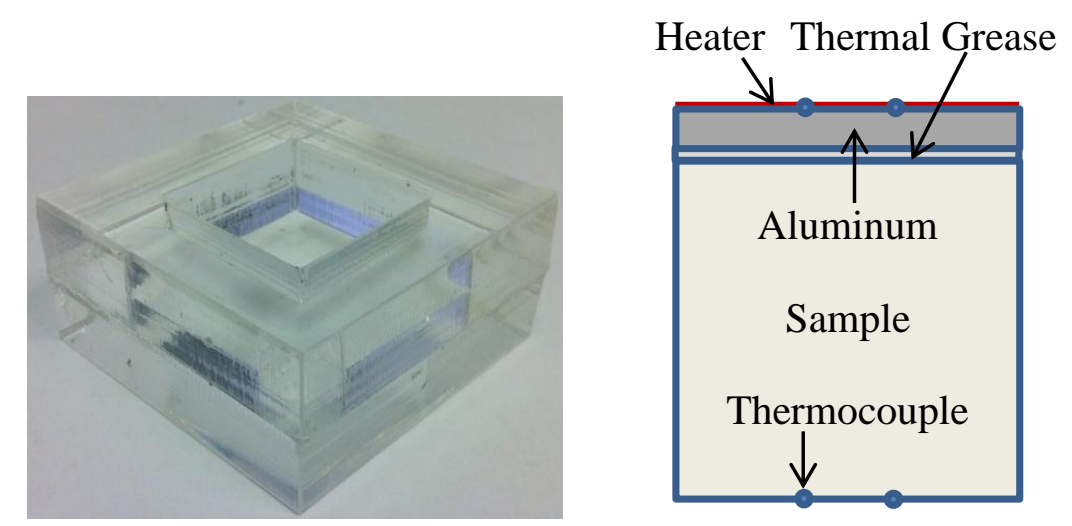

Figure 4. Acrylic container (left); Schematic of test setup for thermal charging experiments (right).

For all experiments, two thermocouples were placed under the heater to measure the top temperature of the composite and two additional thermocouples were placed at the bottom of the sample as shown in Figure 4 (right). It was confirmed that temperature profiles on top of the aluminum plate and under the aluminum plate were the same over time due to the high conductivity of the aluminum. The entire system was placed inside of an insulated box. Type K thermocouples of diameter $0.025 \mathrm{~cm}$ were used in conjunction with a data acquisition unit via a multiplexer to record the thermocouple temperatures. The heaters were powered using a controllable DC power supply during constant heat flux experiments and using a temperature controller during constant temperature experiments. For each constant heat flux and constant temperature experiment, the top and bottom temperatures of the composite were recorded over time. Comparison of the rate at which each portion of the sample increased in temperature relates to the energy storage performance of the system. Values presented for melting time represent averaged values over two repeated experiments per boundary condition and bulk density.

\section{Results and discussion}

3.1. Saturation, thermal conductivity, and latent heat 
During preparation of the composite, saturation with paraffin wax was verified by determining the percent void volume through the measurement of the mass of paraffin in the composite compared to the predicted mass of paraffin based on the known volume and density. It was found that the longer the composite was held under vacuum during paraffin infiltration, the more time the paraffin had to advance through the tortuous network of the CENG to saturate the foam. In Figure 5 (left), the 50 $\mathrm{kg} / \mathrm{m}^{3}$ and $100 \mathrm{~kg} / \mathrm{m}^{3}$ composites show the trend of decreasing void with an increase of time in vacuum. The $100 \mathrm{~kg} / \mathrm{m}^{3}$ composite also indicates a lower limit of about $10 \%$ for the percent void, while the $143 \mathrm{~kg} / \mathrm{m}^{3}$ composites show the repeatability of two different CENG samples in the vacuum for the same period of time. Even though samples were placed in vacuum for 20 hours or more, the percent void is shown to increase as the CENG bulk density increases due the larger number of closed pores formed during the graphite compression process.
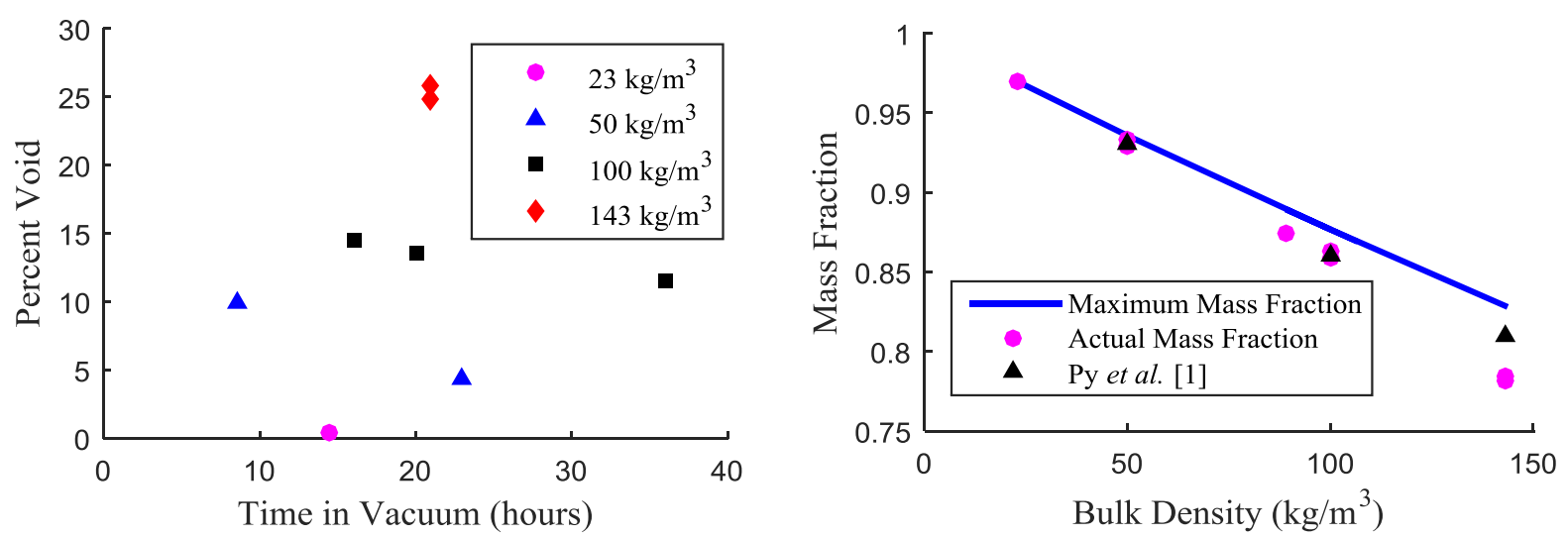

Figure 5. Percent void $( \pm 3 \%)$ as a function of time in the vacuum (left); mass fraction $( \pm 1 \%)$ as a function of CENG bulk density (right).

The mass fraction of the paraffin in the composites, calculated as the mass of paraffin divided by the mass of the sample, is compared to data reported by Py et al. [1] in Figure 5 (right). Though viscosity is not reported in Py et al. [1], generally the viscosity decreases with a decrease in melting temperature. Therefore, the data from Py et al. [1] repeated in Figure 5 (right) is for a melting temperature of $73^{\circ} \mathrm{C}$ as a comparison to the PCM used in this work that melts at $56^{\circ} \mathrm{C}$. The mass fraction data similar to Py et al. [1] was also reported by Mills et al. [8] for a melting temperature of $50^{\circ} \mathrm{C}$. The maximum mass fraction refers to the mass fraction limit if no voids existed in the composite. The impact of percent void is shown by the difference between the actual mass fraction data and the maximum mass fraction. The difference between the actual mass fraction of the composites used in this study and those reported by Py et al. [1], specifically for $143 \mathrm{~kg} / \mathrm{m}^{3}$, is posed 
to be a result of the volume of composite and the time allowed for the composite to absorb paraffin. The volume of each the composites reported in Figure 5 is $120 \mathrm{~cm}^{3}$, while the samples used by Py et al. [1] and Mills et al. [8] were $15.6 \mathrm{~cm}^{3}$ and $1.8 \mathrm{~cm}^{3}$, respectively. Mills et al. [8] also prepared samples with a volume of $49 \mathrm{~cm}^{3}$ and noted a decrease in mass fraction similar to the trend shown in Figure 5 (right). It is noted that the viscosity of the PCM used in this work may also have an impact on the actual mass fraction; however, the work by Py et al. [1] indicates that closed pores as a result of the compression process at high bulk densities are an issue for any viscosity PCM.

Thermal conductivity of the composites is reported in Figure 6 (left). Higher thermal conductivity is exhibited for $100 \mathrm{~kg} / \mathrm{m}^{3}$ and $143 \mathrm{~kg} / \mathrm{m}^{3}$ samples that were measured perpendicular to the direction of compression. This is consistent with previously published data $[1,8,12]$. Latent heat of the composites is reported in Figure 6 (right) by comparing the measured latent heat the composites to that of pure paraffin wax. The data indicates that the latent heat of composites start to significantly decrease at a CENG bulk density of $100 \mathrm{~kg} / \mathrm{m}^{3}$. It is postulated that this effect is a result of increased graphite volume in the system combined with an increased number of closed pores formed during the compression process.
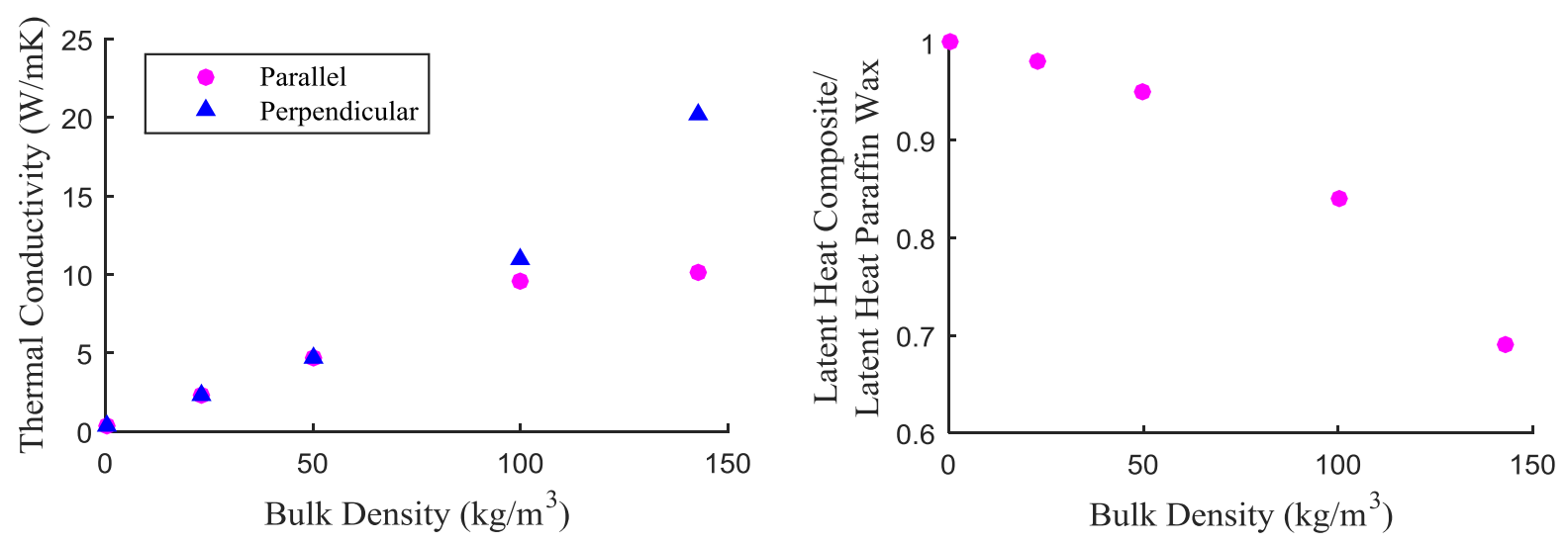

Figure 6. Thermal conductivity $( \pm 2 \%)$ as a function of CENG bulk density and compression (left); Latent heat $( \pm 4 \%)$ as a function of CENG bulk density (right).

\subsection{Thermal charging experiments}

Thermal charging experiments were conducted for composites under various heat flux and temperature boundary conditions. By finding the time at which the bottom of the sample reached the melting temperature as defined by DSC measurements, the time to end of melt was determined for 
each composite to quantify the thermal charging rate. Table 2 summarizes the samples used in thermal charging experiments which have a CENG bulk density range from $0-143 \mathrm{~kg} / \mathrm{m}^{3}$ and thermal conductivity range from $0.3-10.1 \mathrm{~W} / \mathrm{mK}$ along the compression direction and $20.2 \mathrm{~W} / \mathrm{mK}$ perpendicular to the compression direction.

Table 2. Summary of CENG composites.

\begin{tabular}{c|c|c|c}
\hline $\begin{array}{c}\text { CENG Bulk } \\
\text { Density } \\
\left(\mathrm{kg} / \mathrm{m}^{3}\right)\end{array}$ & $\begin{array}{c}\text { Thermal } \\
\text { Conductivity } \\
(\mathrm{W} / \mathrm{mK})\end{array}$ & $\begin{array}{c}\text { Latent } \\
\text { Heat } \\
(\mathrm{J} / \mathrm{g})\end{array}$ & $\begin{array}{c}\text { Melting } \\
\text { Temperature } \\
\left({ }^{\circ} \mathrm{C}\right)\end{array}$ \\
\hline 0 & 0.3 & 163.4 & 55.2 \\
23 & 2.3 & 161.9 & 56.3 \\
50 & 4.7 & 157.0 & 56.3 \\
100 & 9.6 & 136.4 & 54.5 \\
143 & $10.1,20.2^{*}$ & 111.1 & 53.8 \\
\hline \multicolumn{3}{|r}{} \\
\hline \multicolumn{3}{|c}{ *measurement perpendicular to compression }
\end{tabular}

An example of the thermal charging performance is shown by the bottom temperature profile for each composite exposed to $1.55 \mathrm{~W} / \mathrm{cm}^{2}$ shown in Figure 7. The time to end of melt is listed in Table 3 for each composite which can be seen by the transition between solid-liquid phase change and sensible heating at the respective melting temperature listed in Table 2. Figure 7 reflects the relationship between thermal conductivity, latent heat, and time to end of melt. Even though the increase in thermal conductivity associated with an increase in CENG bulk density results in a decrease in time to end of melt, this relationship is not proportional. The 104\% increase in thermal conductivity from $50 \mathrm{~kg} / \mathrm{m}^{3}$ to $100 \mathrm{~kg} / \mathrm{m}^{3}$ results in a decrease in time to end of melt by $19 \%$. Further comparison of the $5 \%$ increase in thermal conductivity from $100 \mathrm{~kg} / \mathrm{m}^{3}$ to $143 \mathrm{~kg} / \mathrm{m}^{3}$ (parallel), results in a decrease in time to end of melt by $15 \%$. The similar impact on melting time with a limited impact on thermal conductivity is due to the decrease in latent heat of the composite as shown in Figure 6 (right); a lower latent reduces the amount of energy stored during phase change, which results in a faster phase change transition. Furthermore, the $100 \%$ increase in thermal conductivity between $143 \mathrm{~kg} / \mathrm{m}^{3}$ parallel and perpendicular samples only decreases the charging rate by $7 \%$. This suggests that comparing CENG composites based only on thermal conductivity is an insufficient metric to understand their thermal charging performance. Additionally, it is important to normalize the thermal charging rate by the composite latent heat since the amount of energy a composite can store will impact the thermal charging rate. 


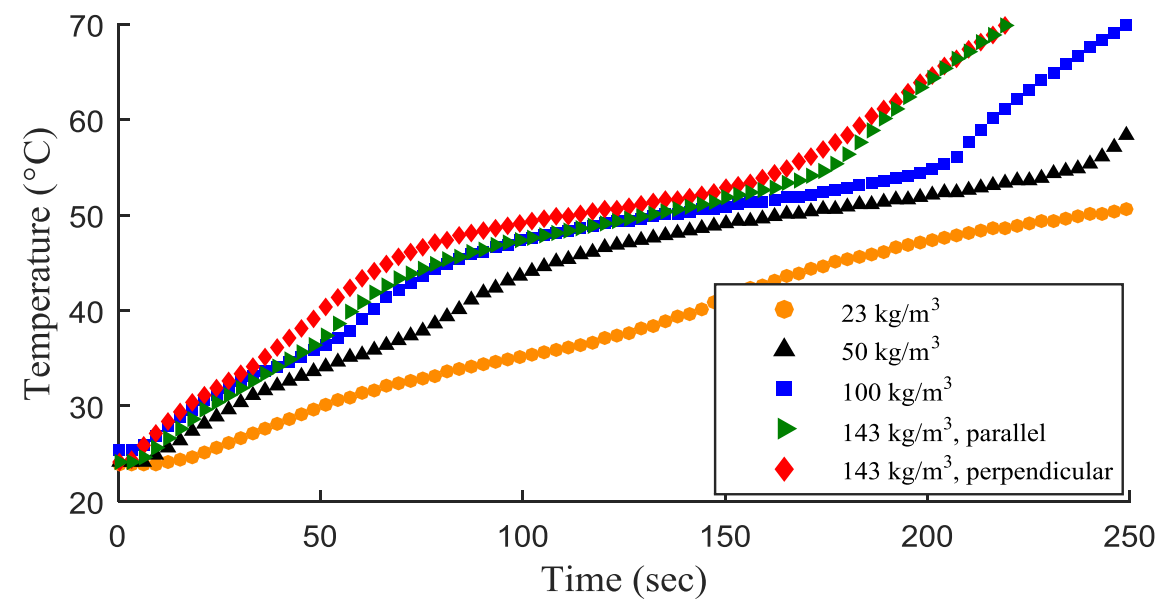

Figure 7. Bottom temperature profile for composites exposed to $1.55 \mathrm{~W} / \mathrm{cm}^{2}$.

Table 3. Time to end of melt for composites exposed to $1.55 \mathrm{~W} / \mathrm{cm}^{2}$.

\begin{tabular}{c|c}
\hline $\begin{array}{c}\text { CENG Bulk Density } \\
\left(\mathrm{kg} / \mathrm{m}^{3}\right)\end{array}$ & $\begin{array}{c}\text { Time to End of Melt } \\
(\mathrm{sec})\end{array}$ \\
\hline 0 & - \\
23 & 355 \\
50 & 243 \\
100 & 198 \\
143 parallel & 169 \\
143 perpendicular & 158 \\
\hline
\end{tabular}

Thermal charging experiments for all composites exposed to $60^{\circ} \mathrm{C}, 0.39 \mathrm{~W} / \mathrm{cm}^{2}, 1.22 \mathrm{~W} / \mathrm{cm}^{2}$, and $1.55 \mathrm{~W} / \mathrm{cm}^{2}$ are summarized in Figure 8. The maximum percent error was calculated to be $4 \%$ of the time to end of melt. Similar to the asymptotic behavior of the time to end of melt as a function of thermal conductivity (Figure 8 (left)), as the latent heat decreases, there is little impact on the time to end of melt after $100 \mathrm{~kg} / \mathrm{m}^{3}$, which corresponds to a latent heat of $136.4 \mathrm{~J} / \mathrm{g}$, although the latent heat exponentially decreases (Figure 8 (right)). Trends in the time to end of melt as a function of composite thermal conductivity and latent heat indicate that additional graphite does not benefit the thermal charging rate beyond a CENG bulk density threshold. 

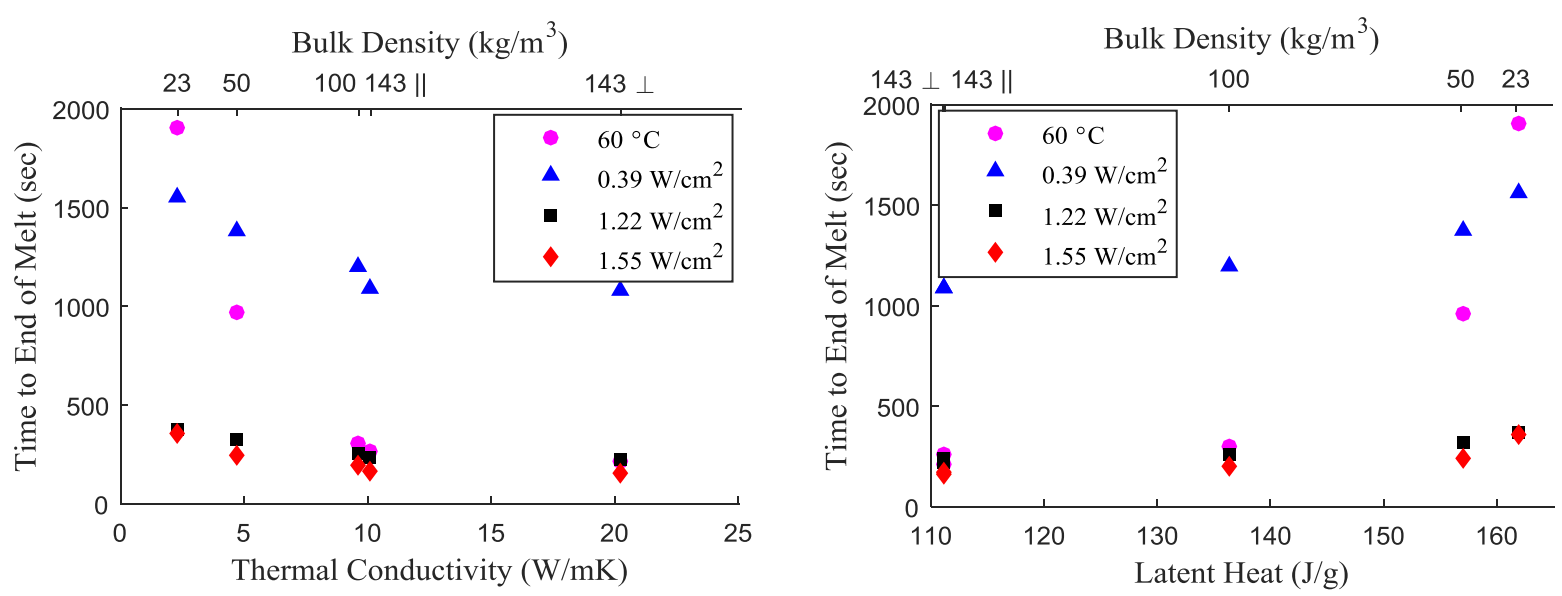

Figure 8. Summary of time to end of melt as a function of thermal conductivity (left) and latent heat (right).

To determine the CENG bulk density threshold for each boundary condition, the time to end of melt and the latent heat measurements were used to find the energy storage, defined as the latent heat divided by the time to end of melt as a function of the CENG bulk density. The calculated maximum percent error is $7 \%$ of the energy storage value. By comparing the rate of increase in energy storage for each boundary condition (constant temperature or constant heat flux), the tradeoff between increased rate of thermal charging and decrease in latent heat is presented. As shown in Figure 9, the benefit of additional graphite beyond $100 \mathrm{~kg} / \mathrm{m}^{3}$ for samples exposed to any boundary condition has limited impact on the energy storage performance. Additionally, the use of a CENG bulk density greater than $100 \mathrm{~kg} / \mathrm{m}^{3}$ actually decreases the energy storage performance for samples measured parallel to compression of the composite as a result of decrease in latent heat.

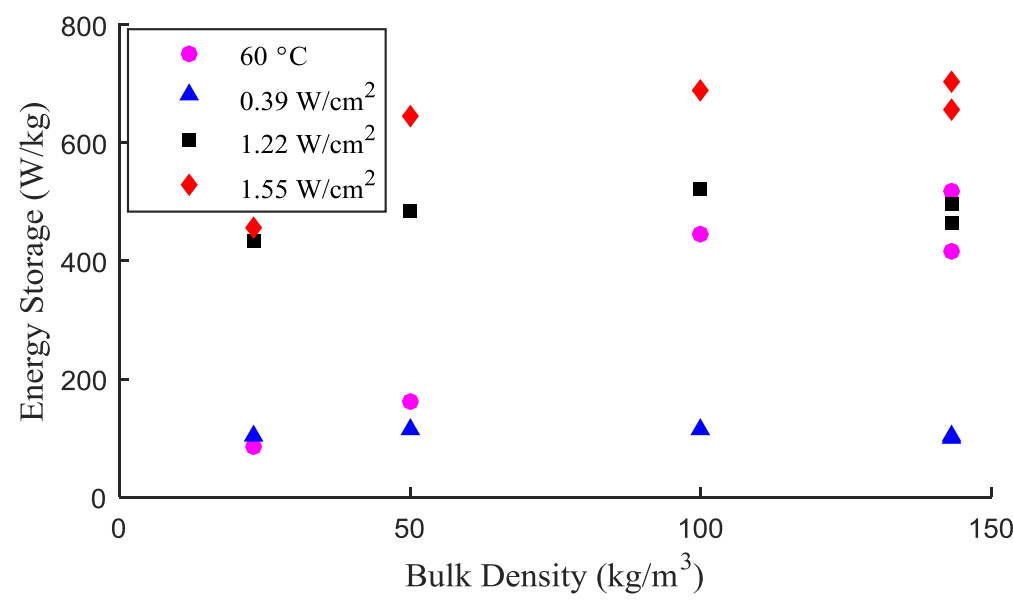

Figure 9. Energy storage performance as a function of the CENG bulk density for different constant heat flux and constant temperature boundary conditions. 


\subsection{Numerical model validation}

Modeling latent heat thermal storage materials introduces an additional degree of non-linearity into the heat transfer problem since thermal energy is stored or released during phase change. In order to describe the temperature distribution through the homogenous medium, the evolution of the phase change boundary through the material must be understood. This moving boundary problem, referred to as the Stefan problem, can be solved analytically, though only feasible for basic 1D analysis, or numerically [7]. The two most common numerical solution methods are referred to as the enthalpy method and the effective heat capacity method $[16,17]$. These methods reformulate the Stefan problem such that the phase change boundary is not explicitly tracked through the material. This is advantageous because, in reality, multiple phase change phenomenon can occur in a material over a non-isothermal temperature range, such as solid-solid crystalline rearrangement later followed by solid-liquid phase change at a higher temperature [18].

The enthalpy method and the effective heat capacity approaches can be extended to study the heat transfer within foams saturated with a phase change material [19]. The small pore size of graphite foam allows the composite to be modeled as a homogeneous material with thermophysical properties adjusted as a function of the volume fraction, $\gamma=V_{\text {foam }} / V_{\text {total }}$. Assuming that natural convection is suppressed in the compressed pores, radiation is negligible, and thermal equilibrium exists between the boundary of the foam and PCM, the governing equation can be transformed with the effective heat capacity as Equation 1. Note that phase change may occur over a range of temperatures, denoted by $\Delta T$, and that the melting temperature is described as $T_{\text {melt }}$ such that $T_{\text {solid }}=\left(T_{\text {melt }}-\right.$ $\Delta T / 2)$ and $T_{\text {liquid }}=\left(T_{\text {melt }}+\Delta T / 2\right)$.

$$
\left(\rho(T) c_{p}(T)\right)_{\text {composite }} \frac{\partial T}{\partial t}=\nabla \cdot\left(k_{\text {composite }} \nabla T\right)
$$

or

$$
\left[(1-\gamma)\left(\rho c_{p}\right)_{P C M}+(\gamma)\left(\rho c_{p}\right)_{\text {graphite }}\right] \frac{\partial T}{\partial t}=\nabla \cdot\left(k_{\text {composite }} \nabla T\right)
$$

where,

$$
\left(\rho c_{p}\right)_{P C M}=\left\{\begin{array}{lr}
\left(\rho c_{p}\right)_{\text {solidPCM }} & T<T_{\text {solid }} \\
\left(\rho\left[\frac{L}{(\Delta T)}+c_{p}\right]\right)_{\text {solidPCM }} & T_{\text {solid }} \leq T \leq T_{\text {liquid }} \\
\left(\rho c_{p}\right)_{\text {liquidPCM }} & T>T_{\text {liquid }}
\end{array}\right.
$$


In this work, the effective heat capacity method with COMSOL is used to numerically model CENG foams saturated with paraffin wax. This model requires knowledge of the density and specific heat in both the solid and liquid phase as well as latent heat and thermal conductivity of the composite. Density and specific heat for the solid and liquid pure PCM were obtained from the manufacturer. Volume fraction and percent void for each CENG foam was used to adjust both the specific heat and density to represent each composite. Latent heat and thermal conductivity are presented in Table 2. Additional properties used in the model are presented in Table 4 assuming $c_{\text {p, graphite }}=711.0(\mathrm{~J} / \mathrm{kgK})$ and $\rho_{\text {graphite }}=2260.0\left(\mathrm{~kg} / \mathrm{m}^{3}\right)$. Note that, since the PCM of interest undergoes both a solid-solid and solid-liquid phase change, the thermophysical properties are presented for both the phase changes.

Table 4. Summary of CENG/PCM composites.

\begin{tabular}{c|c|c|c|c|c|c|c}
\hline \multirow{2}{*}{$\begin{array}{c}\text { CENG } \\
\text { Bulk } \\
\text { Density }\end{array}$} & \multirow{2}{*}{$\begin{array}{c}\text { CENG } \\
\text { Volume } \\
\left(\mathrm{kg} / \mathrm{m}^{3}\right)\end{array}$} & \multicolumn{2}{|c|}{$\begin{array}{c}\text { Density } \\
\left(\mathrm{kg} / \mathrm{m}^{3}\right)\end{array}$} & \multicolumn{2}{c|}{$\begin{array}{c}\text { Specific Heat } \\
(\mathrm{J} / \mathrm{kgK})\end{array}$} & \multicolumn{2}{c}{$\begin{array}{c}\text { Latent Heat } \\
(\mathrm{J} / \mathrm{g})\end{array}$} \\
\cline { 3 - 8 } & Fraction & Solid & Liquid & Solid & Liquid & Solid & Liquid \\
\hline 0 & $0.0 \%$ & 910.0 & 740.0 & 2200.0 & 3000.0 & 31.2 & 132.2 \\
23 & $1.0 \%$ & 923.7 & 755.4 & 2162.9 & 2930.3 & 32.8 & 129.1 \\
50 & $2.2 \%$ & 939.7 & 773.4 & 2120.8 & 2852.1 & 31.2 & 125.8 \\
100 & $4.4 \%$ & 969.4 & 806.9 & 2046.5 & 2716.4 & 25.3 & 111.1 \\
143 & $6.3 \%$ & 995.5 & 836.3 & 1986.1 & 2608.5 & 19.8 & 91.3 \\
\hline
\end{tabular}

The measurements and calculations of Table 4 are used in combination with Equation 1 to model the thermal charging performance of each composite with $\Delta T_{\text {solid-solid }}=14^{\circ} \mathrm{C}$ and $\Delta T_{\text {solid-liquid }}=$ $13^{\circ} \mathrm{C}$ as calculated from DSC measurements. The modeled geometry is shown in Figure 10 (left); a $0.5 \mathrm{~mm}$ layer of thermal grease separates the boundary condition applied to the top surface and the CENG/PCM sample, while the remaining sides are exposed an external heat loss to represent the imperfect insulation of the acrylic experimental container. The initial temperature for the model is defined as the initial temperature of the composite in each respective experiment. The model is validated with prior experimental data by comparing the bottom temperature profile over time under various boundary conditions $\left(60^{\circ} \mathrm{C}, 0.39 \mathrm{~W} / \mathrm{cm}^{2}, 1.22 \mathrm{~W} / \mathrm{cm}^{2}\right.$, and $\left.1.55 \mathrm{~W} / \mathrm{cm}^{2}\right)$ for various bulk densities of graphite $\left(23,50,100,143 \mathrm{~kg} / \mathrm{m}^{3}\right)$. Figure 10 (right) shows comparison of the $23 \mathrm{~kg} / \mathrm{m}^{3}$ and $100 \mathrm{~kg} / \mathrm{m}^{3}$ samples exposed to various boundary conditions. 

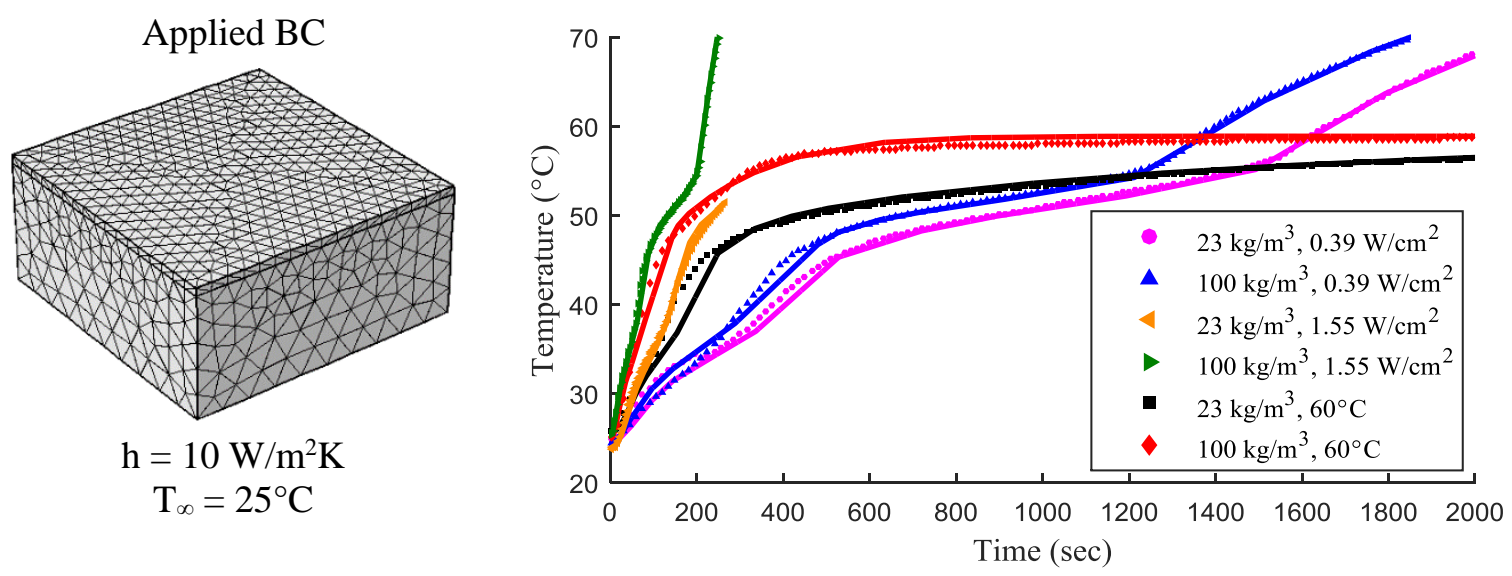

Figure 10. Modeled geometry 2.54 x 2.54 x $1.27 \mathrm{~cm}$ (left); Comparison of model to experimental results. Solid and dotted lines represent numerical and experimental results, respectively (right).

The effective heat capacity assumes an even distribution of latent heat across the temperature range. Comparison of the DSC curve for paraffin wax compared to this assumption is shown in Figure 11 (left). Approximating the normal distributions of latent heat from the DSC curve as average values in both phase change regimes has an implication on the modeled temperature profile. An example of solid-solid phase change is shown in Figure 11 (right). The discrepancy between the temperature profiles of the model and experiment can be attributed to the effective heat capacity assumption; the latent heat is assumed to be constant over the phase change temperature interval, but in reality, this property is a function of temperature.
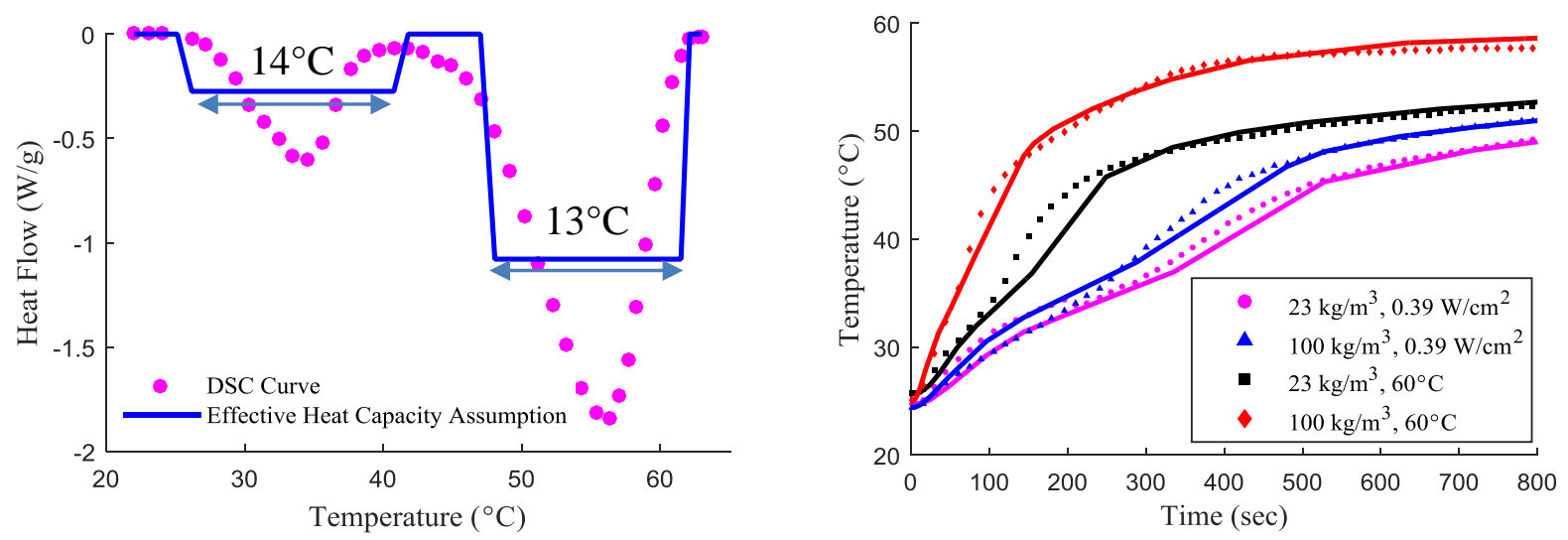

Figure 11. DSC curve compared to effective heat capacity assumption (left); Comparison of model to experimental results in solid-solid regime. Solid and dotted lines represent numerical and experimental results, respectively (right). 
While the effective heat capacity assumption impacts the temperature profiles in the solid-solid and solid-liquid phase change regimes, the validity of this model is suggested by comparing the time to end of melt. For all composites, there is less than $10 \%$ error between the time to end of melt of the model and the experiment. Since the time to fully melt the system is dependent on total latent heat capacity of the system as well as the temperature that the phase transition is complete, which are both accurately reflected in the effective heat capacity assumption, the effective heat capacity model is shown to be a valid model of CENG composites.

The use of the 3D geometry allows comparison of the thermal charging response of the anisotropic $143 \mathrm{~kg} / \mathrm{m}^{3}$ composites by defining the thermal conductivity as $\left[\mathrm{k}_{\mathrm{x}}, \mathrm{k}_{\mathrm{y}}, \mathrm{k}_{\mathrm{z}}\right]_{\text {perpendicular }}=[10.1,10.1,20.2]$ $\mathrm{W} / \mathrm{mK}$ and $\left[\mathrm{k}_{\mathrm{x}}, \mathrm{k}_{\mathrm{y}}, \mathrm{k}_{\mathrm{z}}\right]_{\text {parallel }}=[20.2,20.2,10.1] \mathrm{W} / \mathrm{mK}$. Figure 12 demonstrates the ability of the model to predict this anisotropic response as well as confirms the limited additional benefit of the higher thermal conductivity graphite composite.

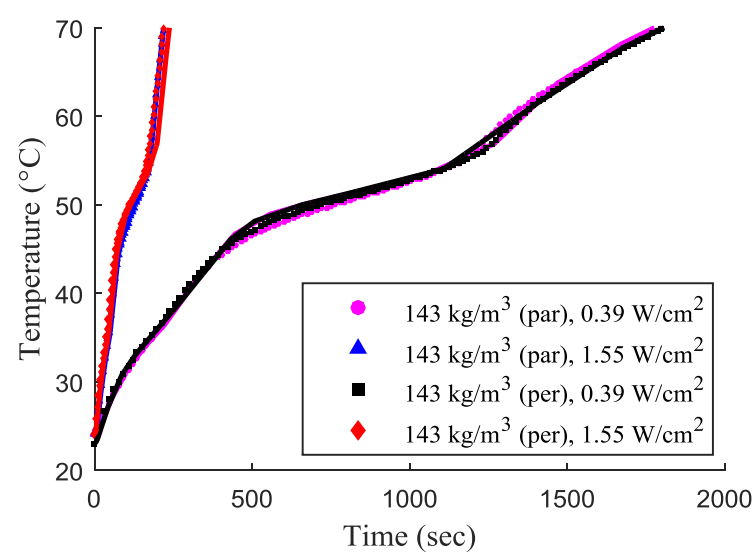

Figure 12. Comparison of model to experimental results for anisotropic graphite composites. Solid and dotted lines represent numerical and experimental results, respectively.

Both the experimental and modeling work in this study suggest that the addition of graphite beyond a CENG bulk density of $100 \mathrm{~kg} / \mathrm{m}^{3}$ has limited benefit on the energy storage performance of the experimental volume. Acknowledging that this practical CENG bulk density limit is height and boundary condition specific, the validated model was used to demonstrate the practical limit of CENG bulk density for systems of various heights and applied heat fluxes. Since the impact of height was the parameter of interest, the model geometry was simplified to a 2D problem as shown in Figure 13 with insulated sides and a lower convection boundary condition to represent imperfect insulation. The height, Y, was varied between $1.27 \mathrm{~cm}$ and $50.8 \mathrm{~cm}$. 


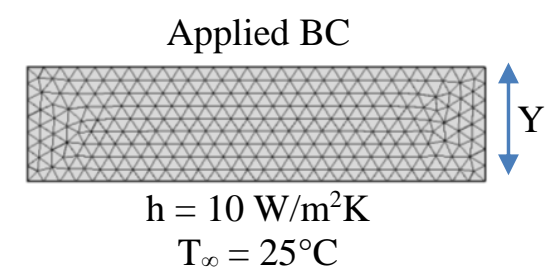

Figure 13. Modeled geometry 5.08 x Y cm.
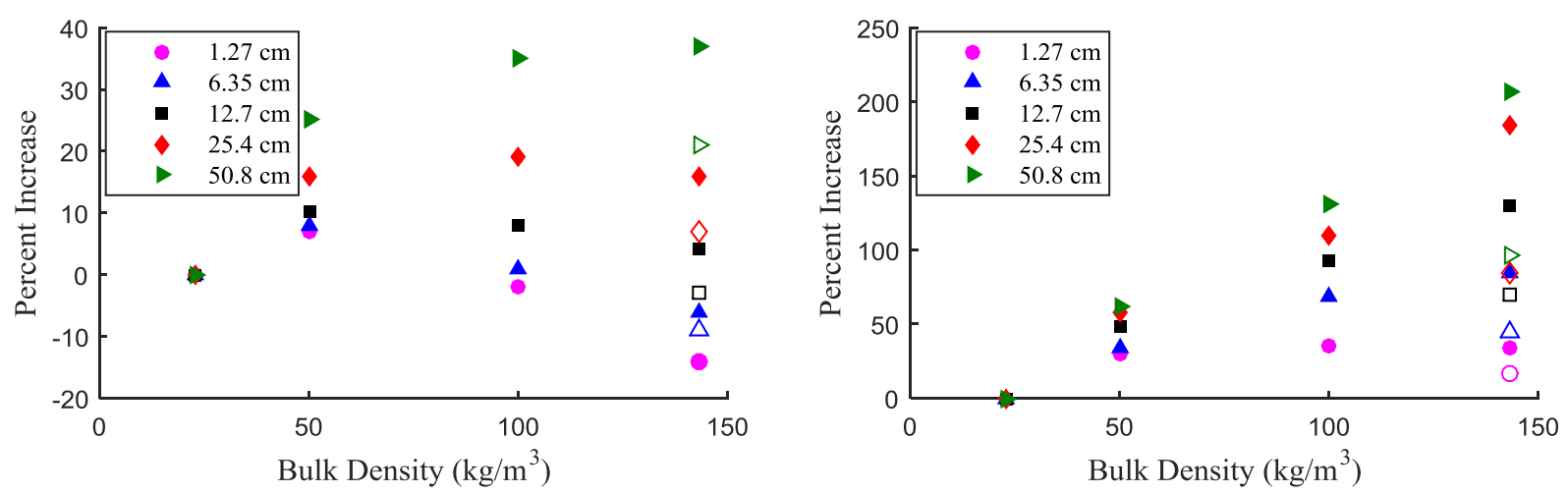

Figure 14. Energy storage performance percent increase compared to $23 \mathrm{~kg} / \mathrm{m}^{3}: 0.2 \mathrm{~W} / \mathrm{cm}^{2}$ (left), 5.0 $\mathrm{W} / \mathrm{cm}^{2}$ (right).

The energy storage performance of CENG composites with bulk densities of $23 \mathrm{~kg} / \mathrm{m}^{3}, 50 \mathrm{~kg} / \mathrm{m}^{3}, 100$ $\mathrm{kg} / \mathrm{m}^{3}, 143$ (parallel) $\mathrm{kg} / \mathrm{m}^{3}$, and 143 (perpendicular) $\mathrm{kg} / \mathrm{m}^{3}$ are compared for various heights and applied heat fluxes in Figure 14. The baseline is considered to be the energy storage performance of $23 \mathrm{~kg} / \mathrm{m}^{3}$. Note that 143 parallel and perpendicular $\mathrm{kg} / \mathrm{m}^{3}$ composites are represented by open and closed data points, respectively, and that the energy storage performance percent increase of the perpendicular sample is always greater than the parallel due to the higher thermal conductivity. As Figure 14 (left) demonstrates, as the height increases for composites exposed to low heat fluxes, the optimum CENG bulk density also increases. Under $0.2 \mathrm{~W} / \mathrm{cm}^{2}, 50 \mathrm{~kg} / \mathrm{m}^{3}$ is the optimum for the 1.27 cm sample, with both $143 \mathrm{~kg} / \mathrm{m}^{3}$ samples actually decreasing the energy storage performance compared to $23 \mathrm{~kg} / \mathrm{m}^{3}$ due to the lower latent heat of the composites. For $25.4 \mathrm{~cm}$, the optimum CENG bulk density changes to $100 \mathrm{~kg} / \mathrm{m}^{3}$, and for $50.8 \mathrm{~cm}, 143 \mathrm{~kg} / \mathrm{m}^{3}$ perpendicular is preferable. As Figure 14 (right) demonstrates the 143 perpendicular composite is preferable for all composite heights exposed to $5.0 \mathrm{~W} / \mathrm{cm}^{2}$ due to the decrease in time to end of melt. The primary assumption in this analysis is the constant boundary condition. In applications with an intermediate heat source, the optimum CENG bulk density will increase; however, due to the decrease in latent heat as the thermal conductivity increases, an optimum CENG bulk density will always exist that maximizes both the thermal charging and energy storage. 
The validated model has also been used to demonstrate the impact of the bulk density, height, and boundary condition on the time to end of melt. To compare all samples, the time to end of melt has been normalized by dividing by the composite height. The normalized time to end of melt for CENG composites with bulk densities of $23 \mathrm{~kg} / \mathrm{m}^{3}, 50 \mathrm{~kg} / \mathrm{m}^{3}, 100 \mathrm{~kg} / \mathrm{m}^{3}, 143$ (parallel) kg/m $\mathrm{m}^{3}$, and 143 (perpendicular) $\mathrm{kg} / \mathrm{m}^{3}$ are compared for various applied heat fluxes in Figure 15. Note that 143 parallel and perpendicular $\mathrm{kg} / \mathrm{m}^{3}$ composites are represented by open and closed data points, respectively.

As shown in Figure 15, the increase in CENG bulk density decreases the normalized time to end of melt for both heat fluxes. This decrease in time to end of melt is due to the increase in thermal conductivity as well as the decrease in latent heat as a result of the addition of graphite (Figure 6). Comparison of the $100 \mathrm{~kg} / \mathrm{m}^{3}$ and 143 (parallel) $\mathrm{kg} / \mathrm{m}^{3}$ data, which have similar thermal conductivities, demonstrates the impact of decreased latent heat: all 143 (parallel) $\mathrm{kg} / \mathrm{m}^{3}$ samples have a normalized time to end of melt less than $100 \mathrm{~kg} / \mathrm{m}^{3}$ due to the decrease in thermal energy capacity. Additionally, comparison of the parallel and perpendicular samples for $143 \mathrm{~kg} / \mathrm{m}^{3}$ show that the higher thermal conductivity of the perpendicular sample results in a lower normalized time to end of melt as compared to the parallel sample. Figure 15 suggests that, for applications where the response rate is more important than the energy storage performance, a higher CENG bulk density is preferable; however, for many thermal storage applications, both the response rate and energy storage density are important parameters to consider.
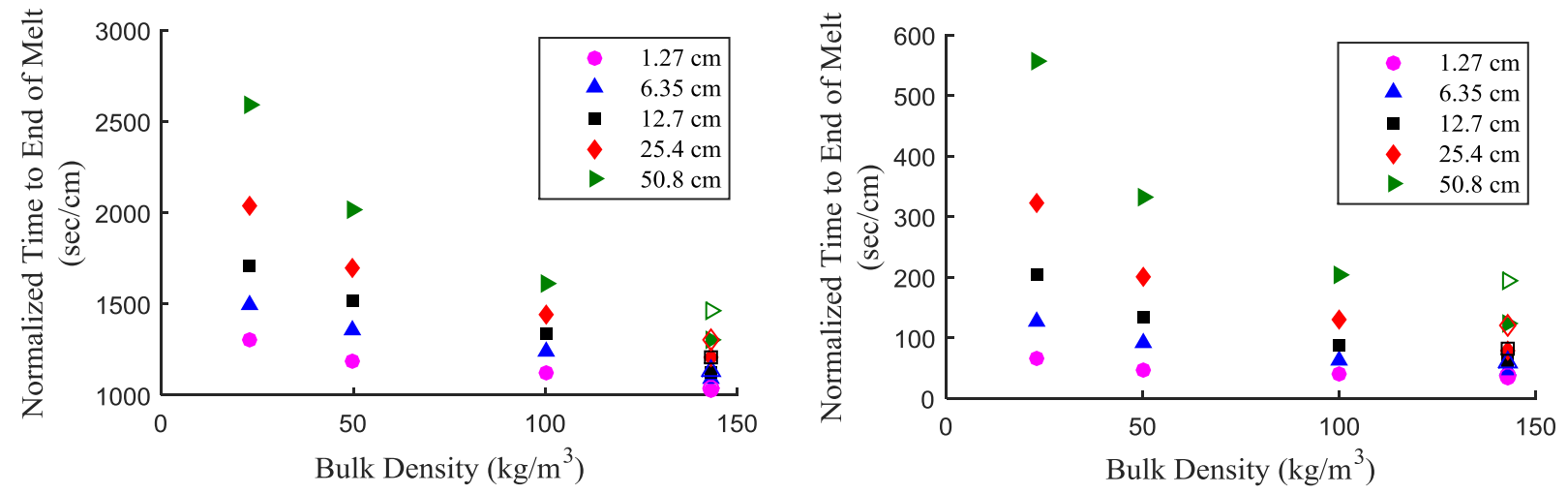

Figure 15. Normalized time to end of melt for various bulk densities: $0.2 \mathrm{~W} / \mathrm{cm}^{2}$ (left), $5.0 \mathrm{~W} / \mathrm{cm}^{2}$ (right). 


\section{Conclusions}

In the design of thermal storage systems, both the charging rate and the energy density of the storage material are important parameters to consider. Since the charging condition is application specific, various boundary conditions were used in the thermal charging study of CENG composites to represent a variety of situations. The use of a standard experimental sample allowed comparisons to be readily made to help elucidate the parameters that govern thermal charging rates in PCM/CENG foam composites. By dividing the latent heat of the composite by the time to end of melt for various boundary conditions and CENG bulk densities, it was shown that all systems approach a practical limit where an increase in CENG bulk density is no longer a benefit for thermal energy storage performance. In some cases, the anisotropic thermal conductivity for high bulk densities actually decreases the thermal storage performance because of the significant impact on latent heat due to the addition of graphite as well as the closed pores formed during compression. These experimental results were used to validate a $3 \mathrm{D}$ phase change model for CENG/PCM composites; the phase change moving boundary problem was solved using the effective heat capacity method and the addition of the graphite foam was represented with a combination of measured and volume averaged properties. This validated model was used to demonstrate the impact of size scale effects on the optimum bulk density. Guided by this work, future effort will focus on developing design rules that consider constraints such as required energy capacity, volume, and response time that improve upon the common metrics of composite thermal conductivity and latent heat for thermal battery design.

\section{Acknowledgements}

The authors are grateful for financial support from the ORNL GO! Program and Mr. Antonio Bouza of the U.S. DOE Building Technologies Office. 


\section{References}

[1] X. Py, R. Olives, and S. Mauran, "Paraffin/porous-graphite-matrix composite as a high and constant power thermal storage material," International Journal of heat and mass transfer, vol. 44, pp. 2727-2737, 2001.

[2] M. R. Anisur, M. H. Mahfuz, M. A. Kibria, R. Saidur, I. H. S. C. Metselaar, and T. M. I. Mahlia, "Curbing global warming with phase change materials for energy storage,"

Renewable and Sustainable Energy Reviews, vol. 18, pp. 23-30, 2013.

[3] C. Y. Zhao, "Review on thermal transport in high porosity cellular metal foams with open cells," International Journal of Heat and Mass Transfer, vol. 55, pp. 3618-3632, 2012.

[4] S. Jegadheeswaran and S. D. Pohekar, "Performance enhancement in latent heat thermal storage system: A review," Renewable and Sustainable Energy Reviews, vol. 13, pp. 22252244, 2009.

[5] C. Y. Zhao, W. Lu, and Y. Tian, "Heat transfer enhancement for thermal energy storage using metal foams embedded within phase change materials (PCMs)," Solar Energy, vol. 84, pp. 1402-1412, 2010.

[6] A. Siahpush, J. O'Brien, and J. Crepeau, "Phase Change Heat Transfer Enhancement Using Copper Porous Foam," Journal of Heat Transfer, vol. 130, p. 082301, 2008.

[7] O. Mesalhy, K. Lafdi, and A. Elgafy, "Carbon foam matrices saturated with PCM for thermal protection purposes," Carbon, vol. 44, pp. 2080-2088, 2006.

[8] A. Mills, S. Al-Hallaj, M. Farid, and J. R. Selman, "Thermal conductivity enhancement of phase change materials using a graphite matrix," Applied Thermal Engineering, vol. 26, pp. 1652-1661, 2006.

[9] A. Sari and A. Karaipekli, "Thermal conductivity and latent heat thermal energy storage characteristics of paraffin/expanded graphite composite as phase change material," Applied Thermal Engineering, vol. 27, pp. 1271-1277, 2007.

[10] L. Xia, P. Zhang, and R. Z. Wang, "Preparation and thermal characterization of expanded graphite/paraffin composite phase change material," Carbon, vol. 48, pp. 2538-2548, Aug 2010.

[11] F. Balima, V. Pischedda, S. Le Floch, A. Brûlet, P. Lindner, L. Duclaux, et al., "An in situ small angle neutron scattering study of expanded graphite under a uniaxial stress," Carbon, vol. 57, pp. 460-469, 6// 2013.

[12] D. Haillot, V. Goetz, X. Py, and M. Benabdelkarim, "High performance storage composite for the enhancement of solar domestic hot water systems: Part 1: Storage material investigation," Solar energy, vol. 85, pp. 1021-1027, 2011.

[13] Z. Ling, J. Chen, T. Xu, X. Fang, X. Gao, and Z. Zhang, "Thermal conductivity of an organic phase change material/expanded graphite composite across the phase change temperature range and a novel thermal conductivity model," Energy Conversion and Management, vol. 102, pp. 202-208, 2015.

[14] D. Haillot, F. Nepveu, V. Goetz, X. Py, and M. Benabdelkarim, "High performance storage composite for the enhancement of solar domestic hot water systems: Part 2: Numerical system analysis," Solar energy, vol. 86, pp. 64-77, 2012.

[15] Y. Zhong, S. Li, X. Wei, Z. Liu, Q. Guo, J. Shi, et al., "Heat transfer enhancement of paraffin wax using compressed expanded natural graphite for thermal energy storage," CARBON, vol. 48, pp. 300-304, 2010.

[16] Y. Dutil, D. R. Rousse, N. B. Salah, S. Lassue, and L. Zalewski, "A review on phase-change materials: mathematical modeling and simulations," Renewable and Sustainable Energy Reviews, vol. 15, pp. 112-130, 2011. 
[17] M. Iten and S. Liu, "A work procedure of utilising PCMs as thermal storage systems based on air-TES systems," Energy Conversion and Management, vol. 77, pp. 608-627, 2014.

[18] P. Lamberg, R. Lehtiniemi, and A.-M. Henell, "Numerical and experimental investigation of melting and freezing processes in phase change material storage," International Journal of Thermal Sciences, vol. 43, pp. 277-287, 2004.

[19] W. Zhao, D. M. France, W. Yu, T. Kim, and D. Singh, "Phase change material with graphite foam for applications in high-temperature latent heat storage systems of concentrated solar power plants," Renewable Energy, vol. 69, pp. 134-146, 2014. 